\title{
ARTIGO
}

\section{O DESENVOLVIMENTO SUSTENTÁVEL COMO UMA ESTRATÉGIA EMPRESARIAL: COMPARATIVO ENTRE DUAS EMPRESAS DO SETOR METALÚRGICO ${ }^{1}$}

\author{
Arnaldo Freitas de Oliveira Júnior ${ }^{2}$ \\ Manoela Sobreira Sodré \\ Marcelo Pablo Borges Lopes \\ Sylvia Karla Candêa
}

\section{RESUMO}

Atualmente, as empresas devem estar atentas quanto às questões ambientais aplicadas em seus processos, uma vez que os órgãos ambientais têm exigido com afinco o cumprimento de legislações, que obrigam estas a investirem em ações que minimizem seus impactos, além da imagem perante a sociedade. Devido a este fato, as empresas vêm buscando ações sustentáveis investindo na preocupação ambiental e sustentabilidade, procurando a valorização no mercado. Com isso, estão definindo metas e implementando sistemáticas para monitorar a eficácia e eficiência dos seus processos quanto ao desenvolvimento sustentável, e criando estratégias que darão suporte para avaliar o seu desempenho ambiental. O estudo é de caráter exploratório e apresenta uma avaliação por meio de entrevistas com duas empresas do setor metalúrgico nomeadas de empresa A que possui um sistema de gestão ambiental e empresa B que atualmente não possui; estão localizadas na cidade de Itaúna, no Centro Oeste mineiro. Serão descritos todos os conceitos relacionados à sustentabilidade e sua importância em termos da contribuição para o desempenho ambiental da empresa e melhoria de sua imagem em termos da responsabilidade. Conclui-se expondo as perguntas e respostas apresentadas na entrevista com as empresas objeto de estudo, e estabelecendo uma abordagem crítica com a demonstração das diferenças entres as mesmas em relação às práticas de desenvolvimento sustentável.

Palavras-chave: Gestão empresarial. Sistema de gestão ambiental. Desenvolvimento sustentável.

\section{INTRODUÇÃO}

A sociedade vive um momento de escassez dos recursos, de um lado a globalização econômica e cultural junto ao desenvolvimento de tecnologias de ponta, e do outro as limitações ambientais que se tornaram emergenciais, exigindo da sociedade a busca por uma existência sustentável.

Nesse contexto a opinião pública tornou-se mais consciente, tanto da limitação no uso dos recursos naturais, quanto das agressões que o meio ambiente vem sofrendo e das suas consequências geradas.

Nos processos produtivos de uma empresa existe também a necessidade de se considerar atitudes sustentáveis para garantir o uso racional dos recursos naturais e dessa forma manter a sua

\footnotetext{
${ }^{1}$ Como citar este artigo: OLIVEIRA JÚNIOR, Arnaldo Freitas de et al. O desenvolvimento sustentável com estratégia empresarial: comparativo entre duas empresas do setor metalúrgico. ForScience: revista científica do IFMG, Formiga, v. 6, n. 2, e00424, out. 2018. Edição Especial.
}

${ }^{2}$ Autor para correspondência: Arnaldo Freitas de Oliveira Júnior, IFTM, e-mail: arnaldojun@ gmail.com. 
disponibilidade. O papel da empresa na sociedade não se restringe meramente à produção de bens ou à prestação de serviços em condições eficientes, assim como não se limita à maximização do lucro para os acionistas. Porém consiste, antes, na geração de riqueza em um sentido mais amplo. Pode se estender além da maximização do lucro, em benefício para os acionistas ou credores, da geração e em manutenção de empregos e do desenvolvimento de infraestrutura de pesquisa, desenvolvimento e comunicações. A empresa passa a incorporar, também, a preservação dos recursos naturais não renováveis, a promoção de direitos fundamentais do trabalhador e a proteção dos interesses do consumidor (ALVES, 2001 apud BENITES; POLO, 2013).

Sendo assim, deve se considerar a importância da gestão empresarial com foco na sustentabilidade, que respeite as relações com o público e com meio ambiente, pela determinação de metas compatíveis com o desenvolvimento sustentável da sociedade, de maneira a preservar recursos ambientais para gerações futuras, respeitando a diversidade e promovendo o decréscimo das desigualdades sociais (MOREIRA; LIMA; TÓTARO, 2013).

Uma empresa comprometida com a sua atuação não se posiciona apenas como geradora de lucros, mas sim como um contribuinte na agregação de valor as suas atitudes e dos demais agentes envolvidos nos seus processos, utilizando assim o desenvolvimento sustentável como estratégia na busca de condições de vida melhores para toda uma comunidade.

Portanto, esse estudo levanta alguns questionamentos sobre a atuação do meio empresarial no que se refere ao desenvolvimento sustentável, sendo: Por que as empresas devem ser sustentáveis? Como o desenvolvimento sustentável pode contribuir para os negócios corporativos? As medidas sustentáveis geram lucro às empresas?

Dessa forma objetiva se expor como se as empresas aplicam medidas sustentáveis e como procedem. Tem-se como objetivos específicos: realizar um comparativo entre uma empresa que aplica práticas sustentáveis e outra que não tem a sustentabilidade como premissa corporativa; saber conforme relato das empresas se conseguem retorno financeiro e uma imagem positiva perante a sociedade com aplicação de medidas sustentáveis; verificar se o desenvolvimento sustentável foi implantado e como é praticado.

A presente pesquisa se justifica pela necessidade de expor ao meio empresarial e a sociedade que é possível realizar estratégias sustentáveis que rendam vantagens e lucros a todos os agentes envolvidos, desde o fornecedor até o consumidor final.

\section{REFERENCIAL TEÓRICO}

Num mundo em que as expectativas da sociedade com relação à adoção de boas práticas pelas empresas são crescentes, a Governança e a Sustentabilidade Corporativa são termos que ganham cada vez notoriedade, a partir da publicação, em 1987, do relatório Brundtland, também intitulado Nosso Futuro Comum ou Our Common Future, que sentou as bases para a definição de desenvolvimento sustentável.

Em 1992, a Conferência das Nações Unidas iniciou uma nova era da Organização das Nações Unidas quanto às discussões e declarações sobre meio ambiente. Como resultado da 
conferência foram publicadas a Declaração sobre Meio Ambiente e Desenvolvimento, a Convenção sobre Mudanças Climáticas, a Declaração de Princípios sobre Florestas, a Convenção sobre a Biodiversidade e Agenda 21. A partir daí lançou-se a noção de três pilares do desenvolvimento sustentável, social, ambiental e econômico. Contudo, para sensibilizar as empresas, o termo usado deveria expressar uma linguagem dos negócios. Em 1994 foi criado o termo triple bottom line, segundo o qual, as corporações são focadas no seu valor econômico, ambiental e social (ANDRÉ, 2015).

Assim, numa realidade em que as empresas apenas se preocupavam com o desenvolvimento econômico o triple bottom line ampliou a visão empresarial na busca de continuidade do mercado e no crescimento organizacional a partir de sua viabilidade econômica e coexistência harmônica com o meio ambiente e sociedade (BENITES; POLO, 2013).

Divulgado em julho de 2000, o Global Compact ou Pacto Global da Organização das Nações Unidas (ONU), visa a promover os valores universais, como justiça, sustentabilidade ambiental e direitos humanos. A criação do Global Compact considerou que as empresas são protagonistas fundamentais no desenvolvimento das nações e devem agir com responsabilidade na sociedade na qual interagem (BENITES; POLO, 2013).

Sanchez (2000) destaca que, uma empresa que adota uma responsabilidade ambiental por processos e produtos, a qual envolve um relacionamento diferente, compartilhado com fornecedores e consumidores no que se refere à prevenção da poluição, à minimização dos resíduos e à proteção dos recursos naturais, engajada assim na cadeia de produção, também adota uma postura na função da administração.

Dessa forma, a cadeia de produção é um conjunto de etapas consecutivas, ao longo das quais os diversos insumos sofrem algum tipo de transformação, até a constituição de um produto final (bem ou serviço) e sua colocação no mercado. A produção mais limpa é um dos objetivos do desenvolvimento sustentável, e conceitua-se como a aplicação contínua de uma estratégia ambiental preventiva, integrada aos processos, produtos e serviços, para aumentar a eficiência global e reduzir riscos para a saúde humana e o meio ambiente. É incorporada nos processos produtivos, em produtos e em serviços (SERVIÇO BRASILEIRO DE APOIO ÀS MICRO E PEQUENAS EMPRESAS, 2012).

Os autores Barbieri, Cajazeira e Branchini (2009) segundo uma perspectiva ambiental, explicam que a cadeia de produção se operacionaliza com a adoção do conceito do ciclo de vida do produto, fazendo-se necessário identificar e quantificar os impactos ambientais ao longo da cadeia, ou seja, além de considerar as etapas envolvidas no processo de produção, distribuição e uso, considerar também as etapas dos fluxos reversos associados à recuperação de materiais processados ou usados para reaproveitá-los novamente.

"Enxergar a cadeia produtiva e não apenas o que se passa no interior da empresa é base para o estabelecimento de boas práticas de gestão e de operação empresarial comprometida com o desenvolvimento sustentável” (BARBIERE; CAJAZEIRA; BRANCHINI, 2009).

Para compreender melhor os termos sustentabilidade e desenvolvimento sustentável é preciso conceituá-los, elucidando assim as suas distinções e correlações.

ForSci.: r. cient. IFMG campus Formiga, Formiga, v. 6, n.2, e00424, out. 2018. Edição Especial. 
O conceito de sustentabilidade tomou maior notoriedade quando foi definido, no relatório de Brundtland (1987), como o processo que supri as necessidades presentes, sem comprometer a capacidade das gerações futuras de suprir suas próprias necessidades. Considera-se a nível organizacional a sustentabilidade empresarial, que busca o equilíbrio sustentável de uma organização enquanto parte do sistema (MUNCK; SOUZA, 2010). Dessa forma, deve se considerar que a sustentabilidade é uma maneira de agir na vida, nos negócios, e nos aspectos que se fizerem necessários, seguindo sempre a premissa de preservar os recursos naturais existentes e garantir assim a sua oferta atual e às próximas gerações.

Enquanto que, segundo o Relatório de Brundtland (1987) o desenvolvimento sustentável é um processo de transformação no qual a exploração dos recursos, a direção dos investimentos, a orientação do desenvolvimento tecnológico e a mudança institucional se harmonizam e reforçam o potencial presente e futuro, a fim de atender às necessidades e aspirações humanas.

O desenvolvimento sustentável alcança maior amplitude, pois deve estar em consonância com os as necessidades nos vários contextos - socioeconômico, ambiental, político e cultural, sendo um conceito de mudança multidimensional (CORREIA; DIAS, 2016). É composto por inúmeras sustentabilidades, e busca o equilíbrio entre os seus vários sistemas, considerando os aspectos ambientais, econômicos, éticos e sociais, sendo uma ferramenta de gestão multissistêmica (MUNCK; SOUZA, 2010). Segundo Mendes (2009) ele abrange diversas dimensões, sendo elas: ecológica, econômica, social, territorial, cultural, política e psicológica.

Deve-se ressaltar que o desenvolvimento sustentável cria vantagem competitiva para as empresas, gera valor para acionistas, consumidores e meio ambiente (PINSKY et al., 2015).

Para que o desenvolvimento sustentável ocorra em uma organização é fundamental que os stakeholders estejam diretamente envolvidos com as estratégias. Os stakeholders são todos os interessados, grupo, indivíduo ou outras organizações, pelo desenvolvimento econômico da empresa e têm habilidade de influenciar nos seus objetivos. Ao negligenciar esses grupos, algumas empresas já foram devastadas ou destruídas.

Não se pode falar de desenvolvimento sustentável como estratégia sem que considere a inovação como uma ação concreta. A inovação sustentável demanda a integração de competências ao longo da cadeia produtiva da empresa, na qual a regulação ambiental incentiva à utilização de novos materiais e tecnologias, diferentes funcionalidades e usos e descartes para os produtos (GONÇALVES-DIAS; GUIMARÃES; SANTOS, 2012). Segundo os autores a inovação é uma tática proveniente de ideias sustentáveis. No quadro 1 é descrito por Pinsky et al.(2015) as diferenças entre cada conceito de inovação.

\begin{tabular}{|c|l|}
\hline Inovação sustentável & $\begin{array}{l}\text { Abordagem de nichos tecnológicos; considera mudanças tecnológicas e } \\
\text { sociais concomitantemente. }\end{array}$ \\
\hline Inovação ambiental & $\begin{array}{l}\text { Orientada predominantemente por regulação ambiental; visa à redução de } \\
\text { custo; não aprofunda na análise do ciclo de vida. }\end{array}$ \\
\hline Eco inovação & $\begin{array}{l}\text { Considera o impacto e avaliação do ciclo de vida; inovação tecnológica, } \\
\text { social e institucional; prioriza o desempenho ambiental em detrimento à meta } \\
\text { ambiental. }\end{array}$ \\
\hline Inovação verde & $\begin{array}{l}\text { O desempenho da inovação considera o posicionamento da empresa e } \\
\text { imagem verde; não aprofunda na análise do ciclo de vida. }\end{array}$ \\
\hline
\end{tabular}

Quadro 1 - Principais diferenças conceituais

Fonte: Pinsky et al. (2015).

ForSci.: r. cient. IFMG campus Formiga, Formiga, v. 6, n.2, e00424, out. 2018. Edição Especial. 
Schaltegger e Wagner (2011) destacam três razões fundamentais para a inovação sustentável quando relacionada ao benefício privado de redução de custos e o benefício social que é gerado, a saber: 1) o benefício privado é maior do que o impacto negativo gerado pela inovação; 2) uma inovação tem um impacto social positivo maior do que o benefício privado; e, 3) os benefícios privado e social equiparam-se. Essas razões são os vetores utilizados pelas empresas para uma análise estratégica fundamentada na sustentabilidade.

No Brasil, há políticas públicas em prol do desenvolvimento sustentável e interesse em aprofundar e desenvolver a chamada economia verde, isso pode ser exemplificado com o evento ocorrido em 2012 na Rio+20, a conferência das Nações Unidas com o objetivo de renovar o compromisso político com o desenvolvimento sustentável foram criados os Objetivos de Desenvolvimento Sustentável (ODS), um conjunto de metas, em processo de finalização que deverá ser assumido por todos os países-membros da ONU após 2015, quando expira o prazo para o cumprimento dos Objetivos do Milênio (ODM) (PINSKY et al., 2015; SANTOS; SOARES, 2016).

Após 2015, construiu-se sobre o legado dos ODM a agenda 2030, assumida como meta pelos países-membros, que definiram os novos Objetivos de Desenvolvimento Sustentável (ODS) para concluir o que estes não conseguiram alcançar. Os ODS permanecerão pelos próximos 15 anos na busca por prosperidade, igualdade e dignidade da pessoa humana (UNITED NATIONS SUSTAINABLE DEVELOPMENT KNOWLEDGE PLATFORM, 2017).

Os ODS são baseados em quatro dimensões que afetam particularmente as empresas: desenvolvimento econômico (incluindo o fim da pobreza extrema), inclusão social, sustentabilidade ambiental e boa governança, considerando a paz e a segurança. Diante desse contexto, é esperado pela sociedade civil que esses ODS norteiem as políticas públicas e privadas das nações nos próximos anos, sendo que as inovações orientadas para a sustentabilidade vão ao encontro das expectativas e metas estabelecidas por meio dos 17 ODS. Em especial ao nono objetivo que é centrado na construção de uma infraestrutura resiliente, no fomento de processos produtivos sustentáveis e inclusivos por meio da inovação (UNITED NATIONS SUSTAINABLE DEVELOPMENT KNOWLEDGE PLATFORM, 2017).

Santos e Soares (2016) refletem que existe um grande desafio que é o cenário mundial compartilhado por todos que buscam soluções de desenvolvimento sustentável para que o plano econômico não mais prejudique o meio ambiente.

Este cenário tem se mostrado um ambiente próspero e vasto de oportunidades aos ecoempreendedores, aqueles que conseguem captar as necessidades, proporem ideias e gerar inovações a partir da consideração da sustentabilidade como um elemento fundamental e assim, construir uma nova forma de gerar negócios lucrativos e ecologicamente corretos. A proposta do eco empreendedorismo é empreender de maneira sustentável ao proporcionar benefícios ao meio ambiente na prevenção ou remediação dos problemas causados por processos produtivos ou criação de produtos (SANTOS; SOARES, 2016).

O Brasil é um país de empreendedores, seja pelo cenário econômico devido ao desemprego e baixos salários, ou pela necessidade de inovar e conquistar espaço no mercado para 
obter lucro. Para Schaltegger e Wagner (2011) a motivação principal do eco empreendedor é contribuir para solucionar algum problema ambiental e criar valor, inovar, sendo seu objetivo principal o retorno financeiro por meio da resolução desses problemas, atendendo assim às demandas do mercado de forma competitiva e contribuindo para o desenvolvimento econômico.

O grande diferencial já não é mais a qualidade, mas sim a postura ética e o comprometimento da empresa com seus acionistas, com a comunidade onde atua, com o meio ambiente e com a sociedade. A estabilidade da empresa, sua imagem perante o público e sua capacidade de satisfazer os seus clientes passam a ocupar papel de destaque (BENITES; POLO, 2013).

Um pesquisa conduzida pelo MIT Sloan Management Review e The Boston Consulting Group em 2012, investigou como as empresas consideram a sustentabilidade relacionada à necessidade e oportunidade, e suas capacidades de implementação de novos modelos de negócios com sucesso. Os resultados evidenciam que o número de empresas que reportam lucro centrado em iniciativas de sustentabilidade aumentou de $23 \%$ para $37 \%$ de 2012 para 2013. Além disso, quase a metade das empresas indicou mudança no modelo de negócio como resultado de oportunidades com foco em sustentabilidade. Nesse sentido, a inovação é uma alavanca voltada para o lucro centrado em novas práticas de sustentabilidade (KIRON et al., 2013).

Os indicadores de desempenho são estratégias a serem adotadas por uma dada indústria e devem fundamentar-se em alguns aspectos, tais como: objetivos da avaliação; abrangência de suas atividades, produtos e serviços; condições ambientais locais e regionais; aspectos ambientais significativos; requisitos legais e outras demandas da sociedade; capacidade de recursos financeiros, materiais e humanos para o desenvolvimento das medições. Em função destes aspectos, deve se diagnosticar os elementos ambientais, relacionados com atividades, produtos e serviços todos prioritários para se iniciar um processo de avaliação de desempenho (CANDÊA, 2010).

Um fator relevante é a finalidade do indicador. Eles servem para medir o grau de sucesso da implantação de uma estratégia em relação ao alcance do objetivo estabelecido. Entretanto, é fundamental que seja observado o fato de que um indicador muito complexo ou de difícil mensuração não é adequado, pois o custo para sua obtenção pode inviabilizar a sua operacionalização (CORAL, 2002).

Os Sistemas de Gestão Ambiental (SGA) é outra estratégia empresarial que surgiu em um cenário de debates a respeito do desenfreado aumento de produção e diminuição de custos buscados por empresas e que acarretaram muitos danos ambientais, fazendo com que as mesmas fossem alvo de críticas e penalidades, fruto de pressão social e de denúncias da mídia, que chegaram a inviabilizar algumas de suas atividades. Como solução a esse impasse, algumas empresas adotaram medidas para diminuir a eliminação de resíduos poluentes e esse foi o início dos sistemas de gestão (DEMAJOROVIC, 1996).

A Gestão Ambiental é uma parte integrante do sistema administrativo geral da organização. A formulação de um SGA é um processo interativo e contínuo. A estrutura, responsabilidade, práticas, procedimentos, processos e recursos para a implementação de 
políticas, objetivos e metas ambientais. O SGA é parte integrante das ações de desenvolvimento sustentável dentro das empresas (CANDÊA, 2010).

A implementação do SGA, além de promover a redução dos custos internos das organizações, aumenta a competitividade e facilita o acesso aos mercados consumidores, além auxiliar no monitoramento dos processos da empresa quanto às questões ambientais e melhoria da imagem das empresas.

Ao gerenciar sistematicamente suas questões ambientais, as organizações devem integrar frequentemente, à administração global. Identificando os aspectos ambientais e os impactos de suas atividades, produtos e serviços, desenvolvendo políticas, objetivos e metas para administrálos; reservar os recursos necessários para uma implementação eficaz, medindo e avaliando o desempenho ambiental e revendo e examinando suas atividades com vista no aperfeiçoamento (CANDÊA, 2010).

Valle (2006) comenta que a gestão ambiental requer como premissa fundamental, um comprometimento da alta administração da organização em definir uma política ambiental clara e objetiva, e isso deve nortear as atividades da organização com relação ao ambiente e também deve ser apropriada à finalidade, à escala e aos impactos ambientais de suas atividades, produtos ou serviços.

Segundo Maimon (1996), pesquisas revelam que medidas de gestão ambiental alteram a imagem da empresa para fins institucionais, e estão se constituindo cada vez mais como prioridades em suas etapas futuras de gestão empresarial e de investimentos financeiros nas empresas brasileiras.

Candêa (2010) considera a política de sustentabilidade como a grande declaração de comprometimento empresarial, relativo ao meio ambiente, constituindo a fundação ou base do sistema de gestão.

Adotando um SGA conforme os requisitos da ISO 14001, a empresa assegura às partes interessadas que atende e respeita a legislação ambiental em sua área de atuação e realiza ações efetivas de gerenciamento e melhorias ambientais.

\section{MATERIAL E MÉTODOS}

O estudo é de caráter exploratório, pois busca o levantamento de informações sobre duas empresas de forma a esclarecer e modificar ideias. Sua abordagem é qualitativa por possibilitar um relacionamento mais flexível e lidar com informações mais subjetivas e com maior riqueza de detalhes, proporcionando profundidade de análise a partir da compreensão do contexto do problema (GIL, 2008).

É baseado em duas vias paralelas que se complementam: por um lado, realizou-se uma pesquisa bibliográfica com a finalidade de buscar conceitos e estabelecer uma estrutura teórica que sustente a análise; por outro, foi feito uma pesquisa empírica com aplicação de uma entrevista semiestruturada com as analistas ambientais, no período de 16 a 20 de outubro de 2017 em duas empresas do setor metalúrgico, sendo que a empresa A utiliza o desenvolvimento 
sustentável como estratégia corporativa, e a empresa B não o utiliza, sendo assim possível verificar as possibilidades que uma gestão sustentável pode oferecer.

Respeitou-se os preceitos éticos com aplicação aos sujeitos envolvidos do termo de consentimento Livre e Esclarecido para a coleta dos dados conforme a Resolução CNS196/96.

A empresa A, de médio porte, localizada em Itaúna no interior de Minas Gerais, atua na fabricação de conexões, corpos de válvulas e acessórios em ferro fundido dúctil para canalizações de água e esgoto e tampões para saneamento, instalações elétricas e de telecomunicações.

A empresa B, de pequeno porte, também localizada em Itaúna, atua no ramo de fundição, desenvolvendo peças sobencomenda em ferro fundido cinzento, branco, nodular e ligado para linha metalmecânica em geral. Está no setor de fundição desde 1996, a empresa mineira, presente também nos estados de São Paulo, Pará, Rio de Janeiro, entre outros.

Ambas atuam no mesmo segmento gerando resíduos semelhantes e adotando as mesmas legislações ambientais.

Os dados foram transcritos e analisados a partir de um comparativo entre as duas empresas entrevistadas.

\section{RESULTADOS E DISCUSSÃO}

A Gestão Ambiental Empresarial é uma das medidas que fazem parte do desenvolvimento sustentável, e pode ser considerada fruto da necessidade do surgimento de um ambiente de negócios mais consciente e capaz de disponibilizar à população produtos e serviços desenvolvidos por meio de processos que preservem o meio ambiente, pois considerando a continuação da tendência atual, a perda do capital natural, vai impactar, em um futuro próximo, as condições de atuação das empresas (ALMEIDA, 2010).

As perguntas abaixo foram aplicadas nas empresas com o objetivo de comparar as práticas adotadas e estabelecer um parâmetro relacionado ao comprometimento e eficácia de seus sistemas de gestão ambiental.

Pergunta 1: A empresa possui alguma certificação ambiental?

Empresa A: "Sim. Possuímos ISO 14001:2004 e caminhamos para um upgrade para a 14001:2015".

Empresa B: Não, mas já iniciou o processo de implementação da ISO 9001(Sistema de Gestão da Qualidade) com data de previsão de certificação até fevereiro de 2018, após esta certificação deseja implementar a ISO 14001 (Sistema de Gestão Ambiental).

Nota se que a empresa A já possui um sistema de gestão ambiental amadurecido e um controle de legislação bem efetivo em função de possuir certificação desde 2007. Já a empresa B está em fase de implantação do seu sistema de gestão iniciando pela base da qualidade. Não foi demonstrado durante a entrevista o interesse em aplicar os requisitos para implantação de um sistema de gestão ambiental, apesar de o órgão ambiental exigir diversos controles e monitoramentos.

ForSci.: r. cient. IFMG campus Formiga, Formiga, v. 6, n.2, e00424, out. 2018. Edição Especial. 
Segundo a Norma NBR ISO 14001:2004, muitas organizações têm efetuado "análises" ou "auditorias" ambientais para avaliar seu desempenho ambiental. Por si só, entretanto, tais "análises" ou "auditorias" podem não ser suficientes para proporcionar a uma organização a garantia de que seu desempenho não apenas atende, mas continuará a atender aos requisitos legais e aos de sua política. Para que sejam eficazes, é necessário que esses procedimentos sejam realizados dentro de um sistema da gestão estruturado que esteja integrado na organização.

Pergunta 2: São desenvolvidos programas ambientais voltados para a comunidade?

Empresa A: Sim. Os resíduos de plástico e papel são doados para a cooperativa de catadores da cidade de Itaúna.

Empresa B: No momento não desenvolvemos estes programas.

Verifica se que a empresa A apresenta uma aplicação de ação efetiva, porém possui suporte para desenvolver outras ações sociais que podem fazer a diferença para a circunvizinhança e apoio a ONGS. Enquanto que a empresa B não desenvolve nenhuma ação de relevância para a sociedade.

A responsabilidade social empresarial é mencionada por Barbiere e Cajazeira (2010) como parte integrante do desenvolvimento sustentável. Para superar os obstáculos existentes referentes ao novo pensamento sustentável, foram construídas duas estratégias: a de pensar globalmente e agir localmente. Ou seja, a empresa não precisa esperar que a legislação local adote medidas responsáveis para começar a pensar e agir de maneira que preserve o meio ambiente em que está inserida.

Pergunta 3: Ao desenvolver seus projetos socioambientais, a empresa busca a parceria de: prefeituras municipais; Polícia Militar e Corpo de Bombeiros; escolas e universidades (públicas ou privadas); igrejas, templos e afins; clubes esportivos e ONG's; órgãos públicos em geral; câmara dos vereadores; outras empresas.

Empresa A: É feito parceria com a Polícia Militar e Corpo de Bombeiros para realização de treinamentos e simulados ambientais. Nas escolas e universidades a empresa oferece o programa de Portas Abertas onde os estudantes podem realizar visitas ou até mesmo desenvolver os seus projetos de pesquisa a partir das instalações e recursos oferecidos.

Empresa B: Não possui parceria.

Nota se a importância das parcerias adotadas pela empresa A, uma vez que possui uma boa imagem empresarial na cidade em função das suas ações comunitárias e relacionamento com seus colaboradores, inclusive os seus filhos são levados para plantar árvores, visitar parques ecológicos e conhecer a planta da empresa, mostrando boas práticas ambientais.

A empresa B não possui um departamento específico para desenvolver ações ambientais e, por isso, apresenta maior dificuldade em implantar projetos e realizar parcerias em função de não traçar objetivos ambientais.

Pergunta 4: A empresa utiliza-se de "marketing ambiental" para divulgar seus projetos de Sustentabilidade? 
Empresa A: Sim, a empresa divulga suas ações ambientalmente corretas, inclusive por meio do site e redes sociais. O grupo cumpre e faz cumprir uma boa conduta ambiental, visando produzir mais gastando o mínimo possível de recursos ambientais.

Empresa B: No momento não é realizado o marketing ambiental.

Segundo os autores Churchill e Peter (2000, p.44), o marketing ambiental consiste em "atividades de marketing destinadas a minimizar os efeitos negativos sobre o ambiente físico ou melhorar sua qualidade."

Pergunta 5: É desenvolvida alguma ação de modo a organizar uma rede de fornecedores socialmente responsáveis/sustentáveis?

Empresa A: Sim. O grupo zela pela qualificação de seus fornecedores, inclusive treina os terceiros com boas práticas de saúde, segurança e meio ambiente. Contratam-se apenas fornecedores ambientais que possuam licenciamento ambiental e que atendem as normas do grupo, como os procedimentos de sistema, instruções de trabalho. Realiza por meio de software de gestão da documentação ambiental como licença ambiental, cadastro técnico federal dos fornecedores.

Empresa B: Sim, já foi implementado um plano de índice de qualidade de fornecimento e um desses critérios é garantir que todos os fornecedores estejam regularmente licenciados e com seu cadastro técnico do Instituto Brasileiro do Meio Ambiente e dos Recursos Naturais Renováveis (IBAMA) em dia.

Nota-se que as duas empresas entrevistadas qualificam sua rede de fornecedores levando em consideração critérios de regularização ambiental e requisitos de qualidade, o que demonstra a grande preocupação da atualidade empresarial, que é a responsabilidade compartilhada durante todo o ciclo de vida da cadeia produtiva dos produtos e serviços.

Boa parte do valor de vendas de uma empresa vem dos seus fornecedores e, por isso, a melhor maneira de obter sucesso é com fornecedores qualificados.

Pergunta 6: A empresa possui políticas formais de compras de "materiais verdes" ou "ambientalmente certificados"?

Empresa A: Sim, todos os materiais como areia, gusa, ferros ligas e serviços são analisados e apenas liberados pela equipe de meio ambiente e segurança do trabalho aqueles que não afetem a saúde e o meio ambiente.

Empresa B: Não.

A empresa A por possuir certificação ISO 14001 já apresenta procedimento documentado em termos de sua lista de fornecedores, e até mesmo registro das ações ambientais que realizaram nos últimos três anos. Já a empresa $\mathrm{B}$, por não possuir sistema de gestão ambiental implementado, não faz um controle formalizado e sistematizado.

Pergunta 7: É desenvolvido algum programa de auditoria de conformidade legal relacionado aos requisitos de meio ambiente?

Empresa A: Sim. Anualmente a empresa realiza uma auditoria de conformidade legal no software de gerenciamento dos requisitos legais relacionados a meio ambiente, saúde e segurança.

ForSci.: r. cient. IFMG campus Formiga, Formiga, v. 6, n.2, e00424, out. 2018. Edição Especial. 
Empresa B: Não, existem apenas requisitos do cliente em termos de qualidade do produto e auditorias internas de gestão da qualidade.

Verifica se a importância das auditorias de conformidade legal realizadas periodicamente pela empresa A, uma vez que estas agregam valor ao sistema de gestão permitindo um acompanhamento do desempenho ambiental e do atendimento efetivo aos requisitos legais.

De acordo com Bettiol (1996) um dos principais benefícios das auditorias de conformidade legal é a avaliação doo cumprimento à legislação ambiental, evitando punições legais do seu não cumprimento. Este autor ainda refere-se aos benefícios quanto à identificação de desperdícios e produtos potencialmente poluidores, otimização do tempo de produção, de matérias-primas, diminuição da geração de resíduos, economia de energia e água, além de estabelecer e manter procedimentos de preparação e atendimento às emergências.

Pergunta 8: A empresa possui indicadores de eficiência ambiental?

Empresa A: Sim, a empresa trabalha com objetivos e metas anuais, todos atualizados mensalmente e apresentados para a toda a planta, através de reuniões, gestão a vista e disseminação por parte dos cargos de liderança para os setores. Assim é monitorado o desempenho do grupo.

Empresa B: Não, existem apenas indicadores de eficiência e eficácia voltados ao desempenho da qualidade como: índice de refugo, satisfação do cliente, prazo de entrega dos produtos, eficácia dos treinamentos, absenteísmo, entre outros.

Para que a empresa garanta o sucesso da implantação de suas ações ambientais torna se fundamental a medição de seu desempenho através de indicadores de eficiência, como realizado pela empresa A. No caso da empresa B percebeu-se que não apresenta os mesmos indicadores de eficiência da empresa anterior, o que dificulta as tomadas de ações de ambientais e sustentáveis.

Para Moreira (2001), monitorar um processo significa acompanhar a evolução dos dados, ao passo que controlá-lo significa mantê-lo dentro dos limites preestabelecidos. Consiste em estabelecer medidas-padrão para a verificação do desempenho ambiental das empresas. Os aspectos ambientais significativos como as emissões atmosféricas, efluentes líquidos, ruídos, etc. - devem ter suas características medidas periodicamente e seus resultados comparados com os padrões legais aplicáveis.

Pergunta 9: A sua empresa/organização tem alguma avaliação sobre a melhoria de sua imagem institucional por desenvolver projetos socioambientais?

Empresa A: $\mathrm{O}$ grupo busca sempre ações que possam beneficiar não apenas os seus negócios, mas também a comunidade, na planta de Itaúna, a qual se refere às respostas deste questionário. É realizado anualmente pesquisa de clima com os funcionários. A empresa possui uma boa imagem no mercado apresentando um alto nível de competitividade e boa saúde financeira.

Empresa B: Não. A empresa não avalia, mas sabe da importância dos projetos socioambientais como ferramenta de competitividade inclusive durante as auditorias de alguns clientes já foram penalizados em suas avaliações por não aplicarem este tipo de projeto.

ForSci.: r. cient. IFMG campus Formiga, Formiga, v. 6, n.2, e00424, out. 2018. Edição Especial. 
As respostas da pergunta 9 evidencia a importância da implementação dos projetos socioambientais como base para melhoria da sua imagem empresarial tornando a mais competitiva e garantindo uma sobrevivência e solidez no mercado.

De acordo com a afirmação de Andrade, Tachizawa e Carvalho (2000) as empresas, que implementam um SGA com um sistema de avaliação da sua imagem institucional, possuem vantagem competitiva no mercado e os aspectos econômicos serão influenciados positivamente.

Pergunta 10: Existe na empresa uma política de Sustentabilidade?

Empresa A: Sim. Além da Política Integrada de Meio Ambiente, Saúde e Segurança o grupo trabalha com princípios de ação sendo um deles voltado para o respeito ambiental. Também foram firmados compromissos internacionais para a redução de consumo de energia elétrica, descarte de água e emissão de gases. Além dos compromissos listados o grupo investe em construções sustentáveis, limitação de impactos ambientais e apoio ao desenvolvimento de comunidades locais.

Empresa B: Não. Apenas possui política da qualidade.

Quando a empresa desenvolve uma política de sustentabilidade é norteada para atingir os seus propósitos, aliando os aspectos ambientais, econômicos e sociais. Infelizmente, a maioria das empresas apenas desenvolve essas políticas fragmentadas a nível ambiental, por ser um requisito obrigatório ao atendimento a ISO 14001.

\section{CONCLUSÃO}

Os dados apresentados nas entrevistas citadas neste trabalho contribuíram de forma significativa para comparar o desempenho ambiental de uma empresa que pratica ações voltadas à sustentabilidade e uma que não atua com a mesma política, uma vez que os dados da entrevista demonstram que a empresa A por possuir um SGA estruturado possui ações e programas ambientais mais efetivos se comparado à empresa B.

Conclui-se que as empresas devem manter a sistemática de aplicação de ações ambientais alinhado a sua evolução empresarial, tecnológica e às necessidades da comunidade.

Reconheceu-se que a implementação de ações sustentáveis, a política de se fazer mais com menos, tornam-se ferramentas muito importantes dentro da estrutura de uma empresa para alavancar o sucesso dos seus negócios com geração de economia dos gastos, manutenção da disponibilidade de recursos naturais com as medidas de racionalização do uso e prevenção de danos ambientais, e realização de ações sociais que mobilizam a comunidade para uma consciência de colaboração coletiva. Além de tudo isso, ainda ocasiona a melhoria da sua imagem perante a sociedade e torna a empresa mais competitiva e sólida no mercado.

Fica o desafio às organizações de implementar e se mobilizar em assumir a preocupação concreta com medidas voltadas ao desenvolvimento sustentável.

ForSci.: r. cient. IFMG campus Formiga, Formiga, v. 6, n.2, e00424, out. 2018. Edição Especial. 


\title{
SUSTAINABLE DEVELOPMENT AS A BUSINESS STRATEGY: COMPARATIVE BETWEEN TWO COMPANIES OF THE METALLURGICAL SECTOR
}

\begin{abstract}
At present, companies must be aware of the environmental issues applied in their processes, since environmental agencies have been demanding to comply with legislation that obliges them to invest in actions that minimize their impacts beyond the image before society. Due to this fact, companies have been seeking sustainable actions by investing in environmental concern and sustainability, looking for appreciation in the market. With this, they are setting goals and implementing systematic to monitor the effectiveness and efficiency of their processes regarding sustainable development and creating strategies that will support to evaluate their environmental performance. The study is exploratory and presents an evaluation by means of interviews with two metallurgical companies named company A that has an environmental management system and company B that currently does not have its own one; they are located in the city of Itaúna, in the western center of Minas Gerais. It will describe all the concepts related to sustainability and its importance in terms of contributing to the company's environmental performance and improving image use in terms of responsibility. It concludes by presenting the questions and answers presented in the interview with the companies under study, and establishing a critical approach with the demonstration of the differences between them in relation to sustainable development practices.
\end{abstract}

Keywords: Business management. Sustainability.Sustainable development.

\section{REFERÊNCIAS}

ANDRADE, R. B.; TACHIZAWA, T.; CARVALHO, A. B. Gestão ambiental: enfoque estratégico aplicado ao desenvolvimento sustentável. São Paulo: Makron Books, 2002.

ANDRÉ, S. C. da S. Gerenciamento de resíduos de serviços de saúde em hospitais do município de Ribeirão Preto-SP: diagnóstico da situação. 2015. 245f. Tese (Doutorado em Ciências) - Escola de Enfermagem de Ribeirão Preto, Universidade de São Paulo, São Paulo, 2015.

ALMEIDA, M. J. L. ISO 14000: gerenciamento ambiental: um novo desafio para a sua competitividade. Rio de Janeiro : Qualitymark, 2010.

BARBIERE, J. C.; CAJAZEIRA, J. E. R. Responsabilidade social empresarial e empresa sustentável: da teoria à prática. São Paulo: Saraiva, 2010.

BARBIERE, J. C.; CAJAZEIRA, J. E. R; BRANCHINI, O. Cadeia de suprimento e avaliação do ciclo de vida do produto: revisão teórica e exemplo de aplicação. O Papel, v. 70, n. 9, p. 52-72, 2009.

BENITES, L. L. L.; POLO, E. F. A sustentabilidade como ferramenta estratégica empresarial: governança corporativa e aplicação do triple bottom line na Masisa. Revista de administração da UFSM, v. 6, edição especial, p. 195-210, 2013. Disponível em:

<https://periodicos.ufsm.br/reaufsm/article/view/8879>. Acesso em: 17 jul. 2018.

BETTIOL, Vanderlei Rodrigo. Benefícios da certificação da ISO 14001. [S.1.]: Universidade de Caxias do Sul - Centro de Ciências Exatas e Tecnologia, 1996. 
CANDÊA, S. K. Os indicadores ambientais como instrumento de gestão para avaliação do desempenho ambiental de uma empresa da cidade de ITAÚNA - MG. 2010. (Trabalho de Conclusão de Curso Engenharia Ambiental) - Centro Universitário de Formiga. Formiga - MG, 2010 .

CHURCHILL, G; PETER, P. J. Marketing: criando valor para os clientes. 2. ed. São Paulo: Saraiva, 2000.

CORAL, E. Modelo de planejamento estratégico para a sustentabilidade empresarial. 2002. 275 f. Tese (Doutorado Engenharia da Produção) - Universidade Federal de Santa Catarina, Florianópolis, 2002.

CORREIA, M. L. A. ; DIAS, E. R. Desenvolvimento sustentável, crescimento econômico e o princípio da solidariedade intergeracional na perspectiva da justiça ambiental. Planeta amazônia: revista internacional de direito ambiental e políticas públicas, Macapá, n. 8, p. 63-80, 2016 .

DEMAJOROVIC, J. A evolução dos modelos de gestão de resíduos sólidos e seus instrumentos. In: Política ambiental e gestão dos recursos naturais. São Paulo: Cadernos Fundap, 1996.

GIL, Antônio Carlos. Métodos e técnicas de pesquisa social. 6. ed. São Paulo: Atlas, 2008.

GONÇALVES-DIAS, S. L. F.; GUIMARÃES, L. F.; dos SANTOS, M. C. L. Inovação no desenvolvimento de produtos "verdes": integrando competências ao longo da cadeia produtiva. Revista de administração e inovação, v. 9, n. 3, p. 129-153, 2012. Disponível em: <https://www.revistas.usp.br/rai/article/view/79279>. Acesso em: 17 jul. 2018.

KIRON, D. et al. The innovation bottom line. MIT Sloan Management Review Research Report. Winter, 2013. Disponível em: <http://sloanreview.mit.edu/projects/ the-innovation-bottom-line/>. Acesso em: 17 jul. 2018.

MAINON, D. Passaporte verde: gestão ambiental e competitividade. Rio de Janeiro: Qualitymark, 1996.

MENDES, J. M. G. Dimensões da Sustentabilidade. Revista das Faculdades Santa Cruz, v. 7, n. 2, p. $49-59$, jul./dez., 2009.

MOREIRA, J. L.; LIMA, L. G. R.; TÓTARO, L. S. Empreendedorismo sustentável: o valor de negócios ambientais. Revista Ex-Xacta, v. 6, n. 12, p. 177-189, 2013. Disponível em: <http://revistas.unibh.br/index.php/dcet/article/view/1083>. Acesso em 17 jul. 2018.

MOREIRA, M. S. Estratégia e implantação do Sistema de Gestão Ambiental (Modelo Série ISO 14000). Belo Horizonte: Editora DG, 2001.

MUNCK, L.; SOUZA, R. B. de. Gestão por competências e sustentabilidade empresarial: em busca de um quadro de análise. Gestão e sociedade, v. 3, n. 6, p. 254-287, 2010. Disponível em: $<$ https://ges.emnuvens.com.br/gestaoesociedade/ article/view/667>. Acesso em 17 jul. 2018.

PINSKY, V. C. et al. Inovação sustentável: uma perspectiva comparada da literatura internacional e nacional. RAI - Revista de administração e inovação, São Paulo, v. 12, n. 3, p. 226-250, 2015. Disponível em: <https://www.revistas.usp.br/rai/article/view/101486>. Acesso em: 17 jul. 2018.

ForSci.: r. cient. IFMG campus Formiga, Formiga, v. 6, n.2, e00424, out. 2018. Edição Especial. 
SANCHEZ, C. Gestão Ambiental Proativa. RAE - Revista de administração de empresas, São Paulo, v. 40, n. 1, p. 76-87, 2000.

SANTOS, D. M. S.; SOARES, M. T. R. C. Novos negócios em gestão ambiental: na visão dos eco empreendedores. In: ENCONTRO DE ESTUDOS SOBRE

EMPREENDEDORISMO E GESTÃO DE PEQUENAS EMPRESAS, 9. , 2016, Passo Fundo. Anais... Passo Fundo, 2016. Disponível em: <http://www.egepe.org.br/2016/artigos-egepe/217. pdf. >. Acesso em: 17 jul. 2018.

SCHALTEGGER, S.; WAGNER, M. Sustainable Entrepreneurship and Sustainability Innovation: Categories and Interactions. Business strategy and the environment, v. 20, p. 222237, 2011. Disponível em: <https://www.researchgate.net/publication/22 7675610_Sustainable_Entrepreneurship_and_Sustainability_Innovation_Categories_and_Interact ions>. Acesso em: Acesso em: 17 jul. 2018.

\section{SERVIÇO BRASILEIRO DE APOIO ÀS MICRO E PEQUENAS EMPRESAS (SEBRAE).} Gestão Sustentável na Empresa. Cuiabá: Sebrae, 2012.

UNITED NATIONS SUSTAINABLE DEVELOPMENT KNOWLEDGE PLATFORM. United nations conference on sustainable development, Rio+20. 2012. Disponível em: <https:// sustainabledevelopment.un.org/rio20>. Acesso em: 08 out. 2017.

VALLE, C. E. Qualidade ambiental: ISO. 6. ed. São Paulo: Senac, 2006.

\section{DADOS DOS AUTORES}

\section{Arnaldo Freitas de Oliveira Júnior}

E-mail: arnaldojun@gmail.com

Currículo lattes: http://lattes.cnpq.br/2754961037728092

Doutor pela Universidade Federal de São Carlos - UFSCar no Departamento de Ecologia e Recursos Naturais em ECONOMIA AMBIENTAL (2003). Mestre pela Universidade Federal de Lavras - UFLA em Fitotecnia, área de concentração: Fitotecnia em Meio Ambiente (1999). Engenheiro Agrônomo pela Universidade Federal de Lavras (1994) Professor em Dedicação Exclusiva do Centro Federal de Educação Tecnológica de Minas Gerais, CEFET-MG junto ao curso de Engenharia Ambiental e Sanitária - DCTA. Professor Adjunto do CEFET - MG. Professor convidado pelo Programa de Mestrado Profissional em Sustentabilidade e Tecnologia Ambiental - IFMG - campus Bambuí.

\section{Manoela Sobreira Sodré}

E-mail: manusobreira@ yahoo.com.br

Currículo lattes: http://lattes.cnpq.br/8065323337028619

Especialista em Emergências, Trauma e Terapia Intensiva pela Faculdade de Ciências Médicas de Minas Gerais (2009). Especialista em Capacitação Pedagógica para Profissionais da Área da Saúde: Enfermagem, pela Universidade Federal de Minas Gerais (2009). Graduada em Enfermagem pelo Centro Univsersitário de Formiga - UNIFOR - MG, (2006). Discente do Mestrado Profissional em Sustentabilidade e Tecnologia Ambiental pelo Instituto Federal de Educação, Ciência e Tecnologia - IFMG - Campus Bambuí.

\section{Marcelo Pablo Borges Lopes}

E-mail: pabloflorestal@yahoo.com.br Currículo lattes: http://lattes.cnpq.br/1489280389407045

Graduado em Engenharia Florestal pela Universidade Federal dos Vales do Jequitinhonha e Mucuri - Campus JK (2008). Técnico em Agrimensura pelo Instituto Educacional Santa Cruz IESC (2015). Especialista em Engenharia de Segurança do Trabalho pela Faculdade Pitágoras de Belo Horizonte (2014). Discente do Mestrado Profissional em Sustentabilidade e Tecnologia Ambiental pelo IFMG - campus Bambuí. 


\section{Sylvia Karla Candêa}

E-mail: sylviakarla@gmail.com

Currículo lattes: http://lattes.cnpq.br/3948868147340135

Especialista em Engenharia de Segurança do Trabalho pela Pontifícia Universidade Católica de Minas Gerais (2012). Graduada em Engenharia Ambiental UNIFOR - MG (2010). Discente do Mestrado Profissional em Sustentabilidade e Tecnologia Ambiental do IFMG - campus Bambuí. 